\title{
Brain hypoxia before surgery; a tale of two cells: Astrocytes and oligodendrocytes
}

\author{
Daniel J. Licht, MD
}

\footnotetext{
From the Department of Neurology and Pediatrics, June and Steve Wolfson Laboratory for Clinical and Biomedical Optics, The Children's Hospital of Philadelphia, Philadelphia, Pa.

D.J.L. is supported by grants from the NINDS (R01NS72338, RO1 NS060653) and by the June and Steve Wolfson Family Foundation.

Disclosures: Author has nothing to disclose with regard to commercial support.

Received for publication Sept 3, 2015; accepted for publication Sept 3, 2015; available ahead of print Oct 10, 2015.

Address for reprints: Daniel J. Licht, MD, Department of Neurology and Pediatrics, Director, June and Steve Wolfson Laboratory for Clinical and Biomedical Optics, Colket Translational Research Building, 10th floor, Room 10030, 3501 Civic Center Blvd, Philadelphia, PA 19104 (E-mail: licht@email.chop.edu).

J Thorac Cardiovasc Surg 2016;151:273-4

$0022-5223 / \$ 36.00$

Copyright (C) 2016 by The American Association for Thoracic Surgery

http://dx.doi.org/10.1016/j.jtcvs.2015.09.026
}

There is now overwhelming evidence that large numbers of survivors of infant heart surgery face significant academic and neurodevelopmental challenges that limit their quality of life and likelihood of successful independence as adults. $^{1,2}$ Early investigations into the risks of poor cognitive outcomes had focused on the conduct of surgery; however, recent pooled data drive home the notion that, despite advances in surgical technique and alternative perfusion strategies, no significant gains have been made in developmental outcomes. ${ }^{3}$ In 2002, the keystone article from Mahle and colleagues ${ }^{4}$ described a highly prevalent form of brain injury to the white matter of the brains of these infants (termed white matter injuryperiventricular leukomalacia [WMI-PVL]). ${ }^{4}$ This imaging finding has been the target of much research by my group and others, as it has offered a plausible surrogate marker for later cognitive outcomes. Longitudinal studies are now emerging that support the link between WMI-PVL and cognitive outcomes. ${ }^{5,6}$ Further support comes from the recent 16-year outcomes from the Boston Circulatory Arrest Trial, where cognitive and performance deficits were associated with abnormalities in very specific white matter tracts $^{7}$ and functional deficits in connectivity. ${ }^{8}$ At the same time, there is a growing literature on how patient factors, such as in utero brain maturation, genetic polymorphisms, and heart defect diagnoses, heavily influence risk for both WMI-PVL and poor cognitive outcomes.

In their study published in this issue of the Journal, ${ }^{9}$ Ishibashi and colleagues, lead author Agematsu, have studied the effects of third-trimester hypoxia on the development of WMI-PVL after surgery. Although this model cannot be considered a fetal model in the strictest sense (it involved postnatal mice), there are some developmental and cellular similarities. The third trimester was targeted in these experiments because that is when we see the divergence from normal brain growth in human

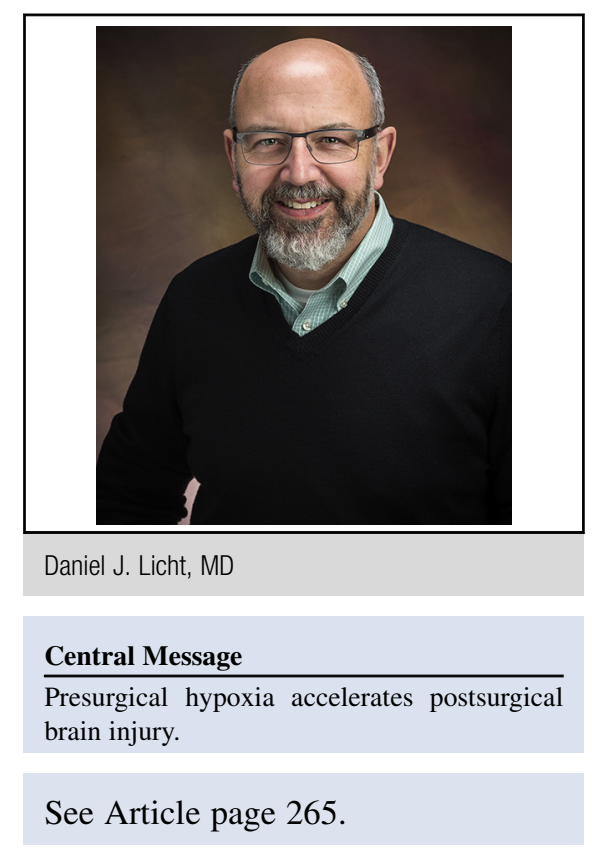

fetuses with congenital heart defects. ${ }^{10}$ We do need to remind ourselves that brain growth is just one marker, and more subtle cellular changes resulting from the altered circulations could be happening at much earlier time points.

To study the effects of presurgical hypoxia, Ishibashi and colleagues developed a very novel rat brain-slice preparation that is supposed to mimic operative conditions of deep hypothermic circulatory arrest (DHCA). This includes the absence of oxygen and glucose delivery to the tissue. With this model, Ishibashi and colleagues elegantly demonstrate that hypoxia before this modeled exposure to deep hypothermic circulatory arrest, similar to what is experienced during heart surgery, results in astroglial cell death, which can be rescued with hypothermic conditions. The results of this exposure model are strikingly similar to human results, in which lower postnatal cerebral oxygen saturations before surgery with deep hypothermic circulatory arrest predicted new and worsened WMI-PVL on postoperative brain MRI. ${ }^{11}$ One wonders whether, if Ishibashi and colleagues were to extend their study and look at variation in the duration of hypoxic exposure before surgery, their results could parallel those of Lynch and colleagues, ${ }^{11}$ who found that increasing time to surgical correction of hypoplastic left heart syndrome was associated with a higher incidence of WMI-PVL.

WMI-PVL has been thought to result from hypoxic ischemic injury to immature oligodendrocytes, which are 
particularly sensitive to injury during the premyelinating stage of development. ${ }^{12}$ The role of the astrocyte in accelerating this injury has not previously been investigated. Through the process of reactive astrogliosis, astrocytes are generally believed to be harmful to white matter repair. In a rat model of fetal intrauterine growth retardation, the expression of bone morphogenetic protein from reactive astrocytes was demonstrated to inhibit oligodendrocyte maturation. ${ }^{13}$ Here, however, the lack of reactive astrogliosis seems to impart a worsening of injury to both immature and mature oligodendrocytes. This finding might not be contradictory, as the hypoxia in this experiment is postnatal, starting at P3 (equivalent to the third trimester in human beings), and not fetal, beginning late in the first trimester. Moreover, astrocyte heterogeneity is well known and often underappreciated in experimental design. Further investigation will be needed.

In the end, our interest in these studies is to plan for neuroprotective strategies. Clearly, the focus has shifted away from "tweaking" surgeries and is concentrated on presurgical and fetal care. Medical in utero interventions have started (https://clinicaltrials.gov/show/NCT02133573), but there are other potential targets. In postnatal human studies, we have found that falling cerebral oxygen saturations between birth and heart surgery predict the development of postoperative WMI-PVL. These brain-slice experiments appear to support this and raise awareness of the role of astrocytes in propagation or acceleration of this injury. These findings will have to be replicated in larger animals (Ishibashi's team is well recognized for work in a porcine model), and the role of astroglial cells and their effect on the oligodendroglia need to be further characterized. There is still much work to be done, both clinically and in the laboratory, but this article opens new avenues for investigation.

\section{References}

1. Goldberg CS, Mussatto K, Licht D, Wernovsky G. Neurodevelopment and quality of life for children with hypoplastic left heart syndrome: current knowns and unknowns. Cardiol Young. 2011;21(Suppl 2):88-92.

2. Villafane J, Lantin-Hermoso MR, Bhatt AB, Tweddell JS, Geva T, Nathan M, et al. American College of Cardiology's Adult Congenital and Pediatric Cardiology Council. d-transposition of the great arteries: the current era of the arterial switch operation. J Am Coll Cardiol. 2014;64:498-511.

3. Gaynor JW, Stopp C, Wypij D, Andropoulos DB, Atallah J, Atz AM, et al. International Cardiac Collaborative on Neurodevelopment (ICCON) Investigators. Neurodevelopmental outcomes after cardiac surgery in infancy. Pediatrics. 2015; $135: 816-25$.

4. Mahle WT, Tavani F, Zimmerman RA, Nicolson SC, Galli KK, Gaynor JW, et al. An MRI study of neurological injury before and after congenital heart surgery. Circulation. 2002;106:1109-14.

5. Andropoulos DB, Ahmad HB, Haq T, Brady K, Stayer SA, Meador MR, et al. The association between brain injury, perioperative anesthetic exposure, and 12-month neurodevelopmental outcomes after neonatal cardiac surgery: a retrospective cohort study. Paediatr Anaesth. 2014;24:266-74.

6. Beca J, Gunn JK, Coleman L, Hope A, Reed PW, Hunt RW, et al. New white matter brain injury after infant heart surgery is associated with diagnostic group and the use of circulatory arrest. Circulation. 2013;127:971-9.

7. Rollins CK, Watson CG, Asaro LA, Wypij D, Vajapeyam S, Bellinger DC, et al. White matter microstructure and cognition in adolescents with congenital heart disease. J Pediatr. 2014;165:936-44. e1-2.

8. Panigrahy A, Schmithorst VJ, Wisnowski JL, Watson CG, Bellinger DC, Newburger JW, et al. Relationship of white matter network topology and cognitive outcome in adolescents with d-transposition of the great arteries. Neuroimage Clin. 2015;7:438-48.

9. Agematsu K, Korotcova L, Morton PD, Gallo V, Jonas RA, Ishibashi N. Hypoxia diminishes the protective function of white-matter astrocytes in the developing brain. J Thorac Cardiovasc Surg. 2016;151:265-72.e1-3.

10. Limperopoulos C, Tworetzky W, McElhinney DB, Newburger JW, Brown DW, Robertson RL Jr, et al. Brain volume and metabolism in fetuses with congenital heart disease: evaluation with quantitative magnetic resonance imaging and spectroscopy. Circulation. 2010;121:26-33.

11. Lynch JM, Buckley EM, Schwab PJ, McCarthy AL, Winters ME, Busch DR, et al. Time to surgery and preoperative cerebral hemodynamics predict postoperative white matter injury in neonates with hypoplastic left heart syndrome. $J$ Thorac Cardiovasc Surg. 2014;148:2181-8.

12. Back SA, Han BH, Luo NL, Chricton CA, Xanthoudakis S, Tam J, et al. Selective vulnerability of late oligodendrocyte progenitors to hypoxia-ischemia. J Neurosci. 2002;22:455-63.

13. Reid MV, Murray KA, Marsh ED, Golden JA, Simmons RA, Grinspan JB. Delayed myelination in an intrauterine growth retardation model is mediated by oxidative stress upregulating bone morphogenetic protein 4. J Neuropathol Exp Neurol. 2012;71:640-53. 